\title{
An opinion paper: emphasis on white muscle development and growth to improve farmed fish flesh quality
}

\author{
J. J. Videler
}

Received: 6 January 2011 / Accepted: 12 January 2011 / Published online: 12 May 2011

(C) The Author(s) 2011. This article is published with open access at Springerlink.com

\begin{abstract}
Due to rapid depletion of wild stocks, the necessity to cultivate fish is eminent. Current fish farming practices seek to improve flesh quality. The notion that white muscles are the main target of the fishing industry is emphasized. A novel approach is suggested based on the development of white muscles in wild fish from eggs to adults. A compilation of facts about white muscle structure, function and ontogeny is followed by an account of the changes in swimming behaviour and performance related to the use of white muscle during growth from larva to adult. Ecological data narrate early swimming performance with white muscle development and growth, unveiling some of the important natural selection factors eliminating weak swimmers and poor growers from the breeding stock. A comparison between fish culture practise and natural conditions reveals fundamental differences. New approaches following wild breeding processes promise several important advantages regarding the quality of white muscle.
\end{abstract}

Keywords Fish culture - White muscle · Myotomes · Myosepts · Larval swimming

J. J. Videler $(\bowtie)$

JOEPvof, Zuidlaarderweg 57, 9479 TH Noordlaren,

The Netherlands

e-mail: j.j.videler@rug.nl

\section{Introduction}

Fish is an important food item for the increasing world population which is rapidly approaching 7 billion people. Fish, one of the main protein sources, is still predominantly caught from the wild. Fishing operations are highly industrialized and effective, with remotely controlled nets, acoustic fish-finders and GPS, resulting in severe depletion of stocks. Total catches decline worldwide despite increased fishing efforts (Pauly 2009). Aquaculture seems the obvious way out, but the fish farming industry currently meets questions regarding fish quality and environmental sustainability.

The fishing industry, including fisheries and fish farming, is in fact targeting white muscle, the main part of fish lateral muscles, since it is preferred for human consumption (Johnston 1999). Many studies discuss the differences in quality between wild and farmed fish, see for example Johnston et al. (2006), Periago et al. (2005) and Verbeke et al. (2007). To a large extend, fish flesh quality depends on muscle characteristics. High-quality traits are high fillet firmness and low lipid contents. Textural firmness is correlated with white muscle fibre density and properties of muscle collagen.

Most fish have two separate muscular engines, one powered by red fibres for slow endured swimming and a much larger white one used for short fast bursts. Small larvae use white fibres predominantly. Adult fish use white muscles occasionally and only during 
short periods of time during fast escape or attack manoeuvres. Unlike terrestrial animals, fish can afford to carry such a bulky specialised engine about because muscle tissue is virtually weightless under water and helps to streamline the body (Videler 1993).

Cultivating fish for food requires knowledge of white muscle ontogeny, functional anatomy and the role in swimming, within the limits of the ecological niche of each species. Novel ideas about improvement of cultivated fish quality must be based on fundamental knowledge about the natural development of the targeted tissue (Johnston 1999). It is of prime importance for the fish food industry to understand what determines the number of white muscle fibres per unit cross-section. The development of white muscle tissue starts early during the embryonic phase and continues in newly hatched larvae. The fibre density in the white muscles is largely determined during the early phases of fish life. An overview of the structure, function, development and ecological role of white muscles under natural selection conditions will be compared with aquaculture practices to detect ways to improve white muscle properties in farmed fish.

\section{Fish white muscles}

The following overview is based on 'Fish swimming' (Videler 1993). Fish are aquatic vertebrates with a skull, a flexible but incompressible vertebral column supporting a medial septum dividing the body into two lateral halves, and lateral longitudinal muscles segmentally arranged in blocks, or myotomes between the sheets of collagenous myosepts. The myotomes are cone-shaped and stacked in a segmental arrangement on both sides of the median septum (Fig. 1a). The muscle segments usually become shorter towards the tail. The length of the cones varies between species. In the caudal region of mackerel (Scomber scombrus), cones span more than 5 vertebrae, in that of cod (Gadus morhua) only 4. In general, shorter segments and a larger number of cones per unit distance along the vertebral column increase the firmness of the lateral muscle.

In cross-sections through the caudal region, the muscles are arranged in four compartments. On each side, there is a dorsal and a ventral compartment, in

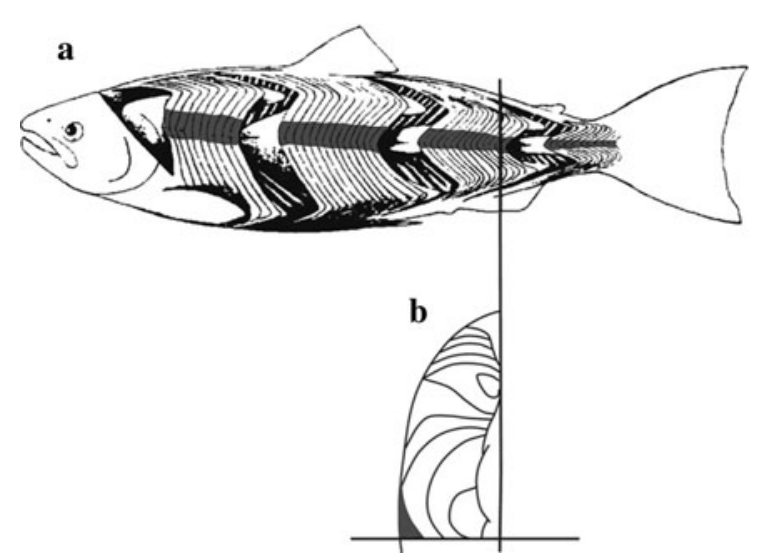

Fig. 1 a The myotomes and myosepts on the left side of the king salmon (Oncorhynchus tshawytscha). Myotomes have been removed at four places to reveal the complex threedimensional configuration of the lateral muscles. Grey area's indicate the position of red muscle tissue. Redrawn after Greene and Greene (1913). b A cross section through the upper left quarter of the caudal region of a salmon. Red muscle fibers are situated in the grey area near the outside. The lines represent the myosepts between the complex myotomes (Based on Shann 1914)

some groups of fish separated by a horizontal septum. The left and right halves and the dorsal and ventral moieties are mirror images of each other. In crosssections, the myosepts are visible as more or less concentric circles of collagen. The arrangement in the ventral part of the abdominal region is different. Myotomes and mysosepts form a flat layer of muscles over the rib cage. The dorsal moieties are continuous with those in the caudal part.

The colour of the muscle fibres may be red, white or intermediate in different locations in the myotomes (Fig. 1b). Red fibres are usually situated directly under the skin. White fibres form the bulk of lateral muscles, and in some species, intermediately coloured pink fibres are found between the two. In some fish, the colour differences are very obvious, but in others, the fibre type distribution is more confusing. The proportion of red muscle is highest in continuously active pelagic fish species (i.e. $15 \%$ of the total muscle mass in mackerel,). Ambush predators and other fish that spend most of the time motionless have predominantly white lateral muscles.

The red fibres are slow but virtually inexhaustible, and their metabolism is aerobic. They react to a single stimulus owing to the high density of nerve terminals on the fibres. The red colour is directly related to the stamina of these muscles because it is 
caused by an extensive blood supply with large amounts of the oxygen-binding protein myoglobin and high concentrations of large mitochondria, the cellular power plants. Cell metabolism is high, and lactic acid is removed quickly. The red muscles of some large tuna and shark species are positioned well inside the white muscle mass, an arrangement which can increase the muscle temperature by as much as $10^{\circ} \mathrm{C}$ during swimming (Carey and Teal 1969). This halves the twitch contraction time of the white muscles and doubles the maximum swimming speed.

The diameter of red fibres is between 20 and 50\% of that of white fibres where values can reach up to $300 \mu \mathrm{m}$.

The white fibres are fast, exhaust quickly and use anaerobic metabolic pathways. The white colour is due to poor vascularisation and lack of myoglobin. Each cell has only a few small mitochondria. It takes up to $24 \mathrm{~h}$ to remove lactic acid after a burst of all out activity. White fibres are either focally or multiply innervated. It is not obvious why white muscles taste better than red muscles. The high concentration of blood in red muscle tissue could be one reason.

During the embryonic stage, the number of developing muscle cells depends on the temperature and oxygen levels (Johnston 2006). The effects of decreased temperatures on the development of fast muscle fibres during this stage vary from no changes in numbers of muscle cells in sea bass (Dicentrarchus labrax), via fewer but larger cells in salmonids, turbot (Psetta maxima) and plaice (Pleuronectes platessa), to more smaller cells in herring (Clupea harengus) and cod. This variation implies that the effect of temperature on the numbers of white fibres at hatching needs to be investigated for each species separately. White muscle fibres start to develop during the early embryonic stages (Johnston et al. 2008, 2009). Towards the end of the egg phase, larvae move vigorously within the confinement of the egg, exercising the white muscle fibres using short bursts of activity. At hatching, the lateral muscles of common carp consist of deep white muscle fibres covered with a monolayer of embryonic red fibres. After hatching, myogenesis continues by the increase in size and in numbers of the fibres present at hatching, see Fig. 2 for the fibre arrangement of carp at first feeding. Carp larvae have the highest growth rates when fed with zooplankton. During the first 2 weeks of feeding, the volume of trunk muscles increased more than 30-fold.

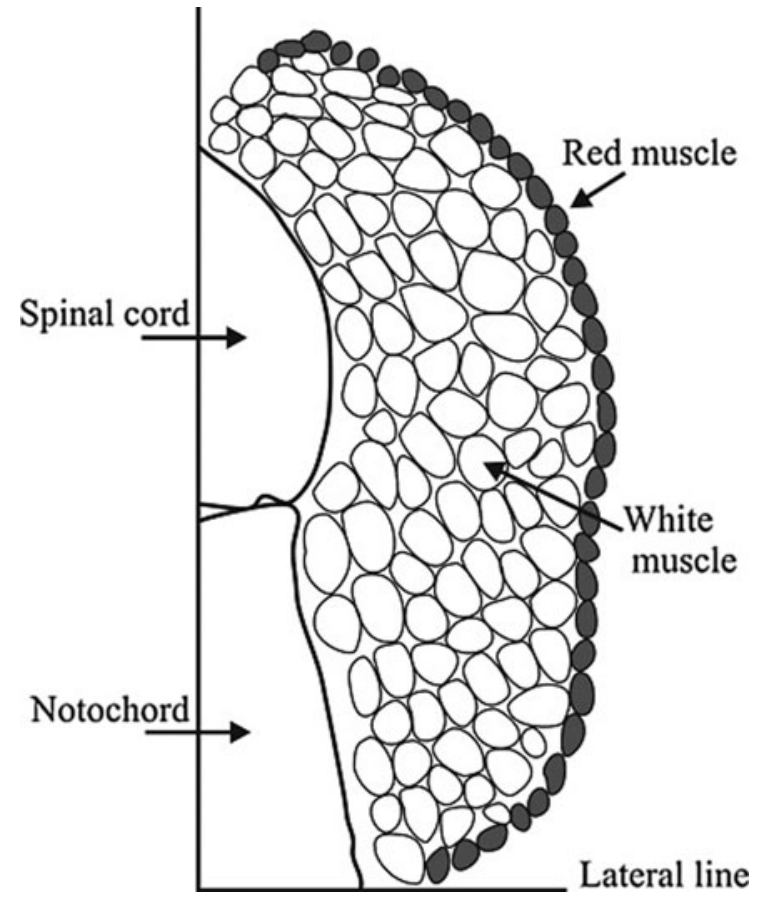

Fig. 2 Schematic representation of one epaxial quadrant of a carp larva at first feeding showing the position of white muscle and the superficial layer of red muscle fibres. Based on AlamiDurante et al. (1997)

Hyperplasia (the increase in cell numbers) was responsible for $64 \%$ of this growth and hypertrophy (the increase in cell size) for 36\% (Alami-Durante et al. 1997).

The increase in white muscle mass depends in a complex way on many environmental conditions, exercise is one of these. Swimming in early larvae differs completely from that of larger stages, and early swimming movements are important for the development of white muscle.

\section{Swimming from larva to adult}

Still inside the egg, fish larvae exercise the white muscle fibres making vigorous body movements. These may continue during the first hours after hatching and turn gradually into coordinated swimming movements after the yolk sac is absorbed (Mauguit et al. 2010). During development from larva to adult, the nature of the interaction between fish and water changes from a viscosity-dominated regime during the early stages, to swimming- 
dominated by inertial forces. The flow regime mainly depends on the size and speed of the fish. The ratio of inertial to viscous forces is conveniently expressed by the dimensionless Reynolds number. Early fish larvae swim in a viscosity-dominated flow regime with Reynolds numbers below 100. Small fish larvae use single tail flicks followed by a very short coast phase. The flick produces two vortices, reaction forces accelerate the larva. For example, a 4-mm-long zebra danio (Brachydanio rerio) larva can reach an initial velocity of $16 \mathrm{~mm} / \mathrm{s}$ with an average acceleration of $200 \mathrm{~mm} / \mathrm{s}^{2}$. The active stroke takes $0.1 \mathrm{~s}$, and the distance covered during the stroke is $1 \mathrm{~mm}$. The initial speed rapidly drops due to the viscous mass of water dragged along by the coasting straight body. The total distance covered while coasting was $1 \mathrm{~mm}$ before the larva came to a halt after $1 \mathrm{~s}$ (Müller et al. 2000). Although the initial velocities reached are high relative to the body length of the larvae, they are very moderate in metres per second. Distances covered during escape responses are extremely small, in the order of a few millimetres. This implies that escape from predators by swimming in an inertial regime is hardly possible. The short tail flicks of escaping and feeding larvae are powered by white muscles. Therefore, this vulnerable life phase is obviously very important for the development and growth of white muscle fibres.

Adult fish operate in inertia-dominated flow regimes with Reynolds numbers well over 1,000. Small adults also often use a few tail beats followed by a gliding phase with the body stretched straight. An adult 35-mm-long zebra danio is able to accelerate at $1,600 \mathrm{~mm} / \mathrm{s}^{2}$ to a speed of $130 \mathrm{~mm} / \mathrm{s}$ using about the same time for the active stroke as the $4 \mathrm{~mm}$ larva. However, the subsequent gliding distance is $30 \mathrm{~mm}$ instead of $1 \mathrm{~mm}$ because the amount of water dragged along is much smaller in proportion to the size of the animal, and both the starting velocity and the inert accelerated mass are higher. This difference implies that the number of potential predators decreases with the size of fish.

Adult fish larger than $10 \mathrm{~mm}$ also swim by continuous lateral undulations of the body. Waves of curvature run from head to tail with increasing amplitude. The speed of the backward wave is higher than the forward speed of the fish. The waves of curvature on the bodies of undulatory swimmers are caused by waves of muscle activations running towards the tail with a $180^{\circ}$ phase shift between the left and the right side (Videler and Wardle 1991). Red muscles power the undulations during routine steady swimming up to a few body lengths per second, and the white muscles of the myotomes are mainly recruited during bursts of fast swimming and startle responses. Fish can swim without getting exhausted at speeds up to approximately 2 body lengths per second while using red muscles only. At higher speeds, white muscles are used, and endurance decreases rapidly to less than a minute above 4 body lengths per second (Videler 1993).

\section{Ecology of larval swimming}

Small fish larvae still experience mortalities close to those of eggs. Their oxygen uptake is restricted because the gills are not functioning optimally due to the high viscosity conditions. Swimming performance is not good enough to escape from most predators. That is the main reason why mortality of plaice larvae for example is $96 \%$ in the first month; only 8 hatchlings out of 100,000 eggs survive the first year. The mortality drops drastically as the larvae grow and swimming performance improves. Temperature clearly affects larval growth. Green and Fisher (2004) found that larvae of the fire clownfish (Amphiprion melanopus) raised in temperatures of 25 instead of $28^{\circ} \mathrm{C}$ had longer larval durations, reduced growth rates and were slower swimmers. Growth

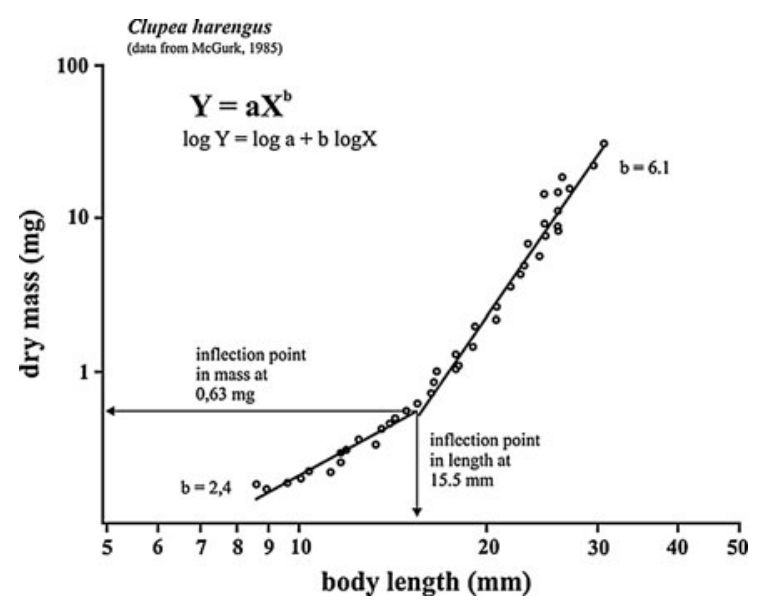

Fig. 3 The inflection point in the growth curve of a herring larva. Note that both scales are logarithmic. Data from McGurk 1985 


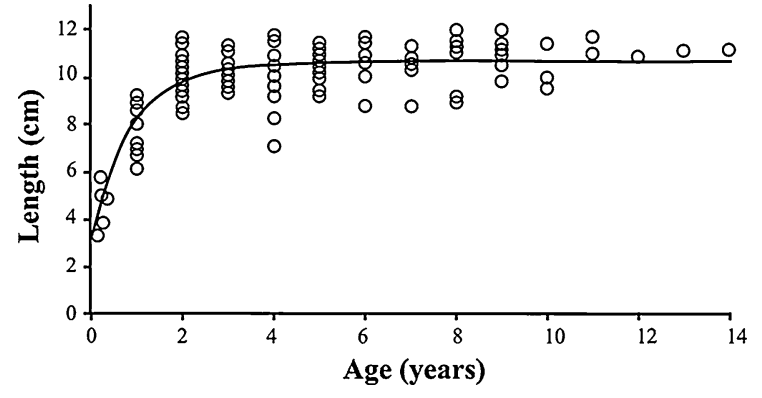

Fig. 4 The growth curve of the brownface butterfly fish (Chaetodon larvatus) in the Southern Red Sea (Zekeria et al. 2006)

curves of many species show an inflexion point indicating faster growth in length during the early stages (Fig. 3) (Müller and Videler 1996). Larvae can escape the viscous regime, and a number of potential predators, by increasing in length and by swimming faster. Length growth does not restrict the amount of developing muscle fibres. Muscles of fast growing carp larvae had a smaller cross-sectional area of muscles with more and thinner fibres than larvae growing slower on a different diet (Alami-Durante et al. 1997). Studies based on back calculations of otolith growth marks showed that faster growing individuals of bluefish (Pomatomus saltatrix) larvae had a higher probability of survival (Hare and Cowen 1997).

A link between condition and mortality was shown in a study of the bluehead wrasse (Thalassoma bifasciatum) by Grorud-Colvert and Ponaugle (2006). The fastest swimmers among larval recruits caught immediately after settlement on the coral reef, grew faster and had a shorter vulnerable pelagic life phase. Meekan et al. (2006) showed that selective mortality in the clupeid Spratelloides gracilis removes small, slow-growing larvae. The size of larvae was principally determined by egg size. During the postlarval stages, no selective mortality could be found. As a reaction to predator pressure, growth curves of many fish species show fast increase in length during the juvenile phase. The brownface butterfly fish (Chaetodon larvatus), for example, grows very fast (Fig. 4) during the first year to reach adult size (Zekeria et al. 2006).

Natural selection processes operate through increased predation on the smaller and least mobile individuals. Small eggs, larvae and juveniles are consumed in large quantities by predators often including larger stages of the same species. Cannibalism is common practise under natural conditions. Only a few survivors reach adulthood to form the next breeding stock.

\section{Fish farming practise in comparison with natural selection}

In contrast to what happens under natural conditions, fish culture seeks to maximise yield during all stages from egg to adult. There is no special attention for the condition and growth of white muscles. Compared with the situation in the wild, swimming opportunities are extremely restricted during all stages of development from larva to adult under most culture conditions. The variety of types of exercise is limited as well as the possibilities to practise certain skills, especially those involving white muscles. Flow channels, induced rotational flows, and other training facilities for fish to improve fish quality in farms will not lead to increased white muscle mass because fish use predominantly red muscles to swim at these speeds (see, i.e., Bjørnevik et al. 2003). On the other hand, forced swimming at moderate speeds of around 1-2 body lengths/s in adults has been shown to provide the best conversion of food into growth in some species (see evidence reviewed in Jobling et al. 1993; Videler 1993). It is unclear how much of the increase in body weight is due to white muscle mass enhancement. Improved physiological performance and reduced frequencies of aggressive interactions are probably partly responsible for this effect.

Lack of exercise and high feeding rates make reared fish shorter and fatter (Blaxter and Hunter 1982). Behaviour in captivity in most cases differs tremendously from that in the wild. Fish do not need to forage and lack the threat of predation. There are no natural predators, and hence, escape movements are scarcely practised. Food usually comes in the form of pellets which do not require natural attack strategies. Pelagic species are not equipped to deal with confinement and confrontation with obstacles. Resulting stress will have a negative effect on healthy growth. Crowding, even for schooling fish, seriously affects development and growth (Santos et al. 2010). In Atlantic salmon, crowding of more than $200 \mathrm{~kg}$ fish $/ \mathrm{m}^{3}$ changes structural muscle proteins and enzymes involved in energy production (Veiseth-Kent et al. 2010). It will cause 
unnatural and chaotic flow patterns and an overload of information through the lateral line system to the brain (in humans information overload in the brain causes psychosis). Densities can be up to 1,000 times the natural conditions.

Fish farming also applies selection pressures on the farmed populations, either on purpose or as a side effect of management practises. These are aimed at maximum survival rates and will finally result in changes in the inherited properties of the species concerned. Farming conditions do not allow optimal development and training possibilities for white muscle. Therefore, the quality of the white muscle can be expected to decrease as a consequence of the lack of selection for the use of that tissue throughout the development from egg to adult.

Regarding the fundamental differences between farming and natural conditions, it does not come as a surprise that the quality of the white muscle of farmed fish deviates from that of wild conspecifics (Santos et al. 2010).

The implicit goal in fish culture is the aim to produce fish for human consumption which cannot be distinguished from wild fish. That goal could be approached by copying the natural selection processes as closely as possible during the entire life cycle of fish in captivity and by offering close to natural ecological conditions.

The largest eggs should be selected to start the production process using larvae with the highest number of white muscle cells. During the egg stage, white muscle fibres develop depending on temperature and oxygen levels in a complicated and different way for each species. The general trend is that the biggest eggs produce the largest larvae with the highest survival chances. Large eggs offer the embryo ample opportunity to develop and train white muscle cells. After hatching, hunting for live food will induce kick and glide swimming, which promotes white muscle development and growth.

During the adult phase, animals should be able to hunt for or gather food in a natural way to maintain optimal conditions and to avoid the accumulation of fat inside the white muscle tissue.

Acknowledgments I am grateful to Josep Planas and Arjan Palstra for the invitation to present this paper at the Fitfish conference 2010 in Barcelona. Ulrike Müller made Fig. 3. Yohannes Afeworki introduced me to parts of the literature I might otherwise have overlooked.
Open Access This article is distributed under the terms of the Creative Commons Attribution Noncommercial License which permits any noncommercial use, distribution, and reproduction in any medium, provided the original author(s) and source are credited.

\section{References}

Alami-Durante H, Fauconneau B, Rouel M, Escaffre AM, Bergot P (1997) Growth and multiplication of white skeletal muscle fibres in carp larvae in relation to somatic growth rate. J Fish Biol 50:1285-1302

Bjørnevik M, Karlsen Ø, Johnston IA, Kiessling A (2003) Effect of sustained exercise on white muscle structure and flesh quality in farmed cod (Gadus morhua L.). Aquac Res 34:55-64

Blaxter JHS, Hunter JR (1982) The biology of the clupeoid fishes. Adv Mar Biol 20:1-22

Carey FG, Teal JM (1969) Regulation of body temperature by the bluefin Tuna. Comp Biochem Physiol 28:205-213

Green BS, Fisher R (2004) Temperature influences swimming speed, growth and larval duration in coral reef fish larvae. J Exp Mar Biol Ecol 299(1):115-132

Greene CW, Greene CH (1913) The skeletal musculature of the king salmon. Bull US Bur Fish 33:21-60

Grorud-Colvert K, Ponaugle S (2006) Influence of condition on behavior and survival potential of a newly settled coral reef fish, the bluehead wrasse Thalassoma bifasciatum. MEPS 327:279-288

Hare JA, Cowen RK (1997) Size, growth, development, and survival of the planktonic larvae of pomatomus saltatrix (pisces: pomatomidae). Ecology 78(8):2415-2431

Jobling M, Baardvik BM, Christiansen JS, Jørgensen EH (1993) The effects of prolonged exercise training on growth performance and production parameters in fish. Aquac Int 1:95-111

Johnston IA (1999) Muscle development and growth: potential implications for flesh quality in fish. Aquaculture 177: 99-115

Johnston IA (2006) Environment and plasticity of myogenesis in teleost fish. J Exp Biol 209:2249-2264

Johnston IA, Li X, Vieira VLA, Nickell D, Dingwall A, Alderson R, Campbell P, Bickerdike R (2006) Muscle and flesh quality traits in wild and farmed Atlantic salmon. Aquaculture 256:323-336

Johnston IA, Macqueen DJ, Watabe S (2008) Molucular Biotechnology of development and growth in fish muscle. In: Tsukamoto K, Kawamura T, Takeuchi T, Beard TD Jr, Kaiser MJ (eds) Fisheries for global welfare and environment, 5th World Fisheries Congress 2008, 241-262

Johnston IA, Lee H-T, Macqueen DJ, Paranthaman K, Kawashima C, Anwar A, Kinghorn JR, Dalmay T (2009) Embryonic temperature affects muscle fibre recruitment in adult zebrafish: genomewide changes in gene and microRNA expression associated with the transition from hyperplastic to hypertrophic growth phenotypes. J Exp Biol 212:1781-1793

Mauguit Q, Gennotte V, Becco C, Baras E, Vandewalle N, Vandewalle P (2010) Ontogeny of swimming movements in the catfish Clarias gariepinus. Open Fish Sci J 3:16-29 
McGurk MD (1985) Multivariate analysis of morphometry and dry weight of Pacific herring larvae. Mar Biol 86:1-11

Meekan MG, Vigliola L, Hansen A, Doherty PJ, Halford A, Carleton JH (2006) Bigger is better: size-selective mortality throughout the life history of a fast-growing clupeid, Spratelloides gracilis. MEPS 317:237-244

Müller UK, Videler JJ (1996) Inertia as a 'safe harbour': do fish larvae increase length growth to escape viscous drag? Rev Fish Biol Fish 6:353-360

Müller UK, Stamhuis EJ, Videler JJ (2000) Hydrodynamics of unsteady fish swimming and the effects of bodysize: comparing the flow fields of fish larvae and adults. J Exp Biol 203:193-206

Pauly D (2009) Aquacalypse now. The New Republic Sept. 28:pp 1-3

Periago MJ, Ayala MD, López-Albors O, Abdel I, Martínez C, García-Alcázar A, Ros G, Gil F (2005) Muscle cellularity and flesh quality of wild and farmed sea bass, Dicentrarchus labrax L. Aquaculture 249:175-188

Santos GA, Schrama JW, Mamauag REP, Rombout JHWM, Verreth JAJ (2010) Chronic stress impairs performance, energy metabolism and welfare indicators in European seabass (Dicentrarchus labrax): the combined effects of fish crowding and water quality deterioration. Aquaculture 299(1-4):73-80

Shann EW (1914) On the nature of the lateral muscle in teleostei. Proc Zool Soc Lond 22:319-337

Veiseth-Kent E, Grove H, Færgestad EM, Fjæra SO (2010) Changes in muscle and blood plasma proteomes of Atlantic salmon (Salmo salar) induced by crowding. Aquaculture 309:272-279

Verbeke W, Sioen I, Bruns $\varnothing$ K, de Henauw S, van Camp J (2007) Consumer perception versus scientific evidence of farmed and wild fish: exploratory insights from Belgium. Aquac Int 15:121-136

Videler JJ (1993) Fish swimming. Chapman and Hall, London

Videler JJ, Wardle CS (1991) Fish swimming stride by stride: speed limits and endurance. Rev Fish Biol Fish 1:23-40

Zekeria ZA, Weertman S, Samuel B, Kale-ab T, Videler JJ (2006) Growth of Chaetodon larvatus (Chaetodontidae: Pisces) in the southern Red Sea. Mar Biol 148:1113-1122 